\title{
Evaluación de sistemas de labranza sobre propiedades físico-químicas y microbiológicas en un Inceptisol
}

\author{
Evaluation of tillage systems on physical-chemical and microbiological \\ properties in an Inceptisoil
}

\section{Dayra Yisel García R. ; Julian Fernando Cárdenas H.; Amanda Silva Parra ${ }^{3}$}

1 Docente, Especialista en Gestión Ambiental Sostenible, Estudiante de Maestría en Producción Tropical Sostenible, Universidad de los Llanos, Villavicencio, Colombia, dgarcia@unillanos.edu.co.

2 Docente Asistente, Magister en Ciencias Agrarias, Facultad de Ciencias Agropecuarias y Recursos Naturales, Universidad de los Llanos, Villavicencio, Colombia, jfcardenas@unillanos.edu.co

3 Docente Asistente, Doctora en Agronomía Ciencia del Suelo, Facultad de Ciencias Agropecuarias y Recursos Naturales, Universidad de los Llanos, Villavicencio, Colombia, asilvap@unillanos.edu.co

Citar: García, D., Cárdenas, J. \& Silva, A. (2018). Evaluación de sistemas de labranza sobre propiedades físicoquímicas y microbiologicas en un inceptisol. Rev.Cienc. Agr. 35(1): 16-25. doi:http://dx.doi.org/10.22267/ rcia.183501.79.

Recibido: Febrero 10 de $2017 . \quad$ Aceptado: Febrero 27 de 2018.

\section{RESUMEN}

A partir de los efectos negativos de la labranza convencional en Inceptisoles de Villanueva, departamento del Casanare, Oriente de Colombia, la presente investigación evaluó el impacto de tres sistemas de labranza: T1: Labranza reducida (desbrozadora, un pase de cincel vibratorio, un pase de rastra y siembra), T2: siembra directa y T3: labranza de conservación (desbrozadora, un pase de cincel vibratorio, siembra con 30\% de cobertura) sobre algunas variables físicas, químicas y biológicas del suelo, como la densidad aparente (Da), porosidad (n), porcentaje de materia orgánica del suelo (\%MOS) y unidades formadoras de colonias de hongos y bacterias UFCs. Se utilizó un Diseño de Bloques Completamente al Azar con tres tratamientos y cinco repeticiones para 15 unidades experimentales, evaluados en dos épocas: M1: antes de la preparación y M2: después de dos meses de siembra de maíz. Se realizó Análisis de Varianza y la Prueba de Comparación de Medias de Tukey ( $\mathrm{p} \leq 0.05)$. La Da fue más alta en T1 (1,52g/ cm3) en M1. Con el T3 se alcanzó una Da más baja en ambas épocas $(1,27 \mathrm{~g} / \mathrm{cm} 3)$. La porosidad fue mayor con el T3 sin diferencias entre muestreos. T2 ocasionó un mayor porcentaje de MOS en M2. T3 presentó mayores UFCs de hongos y bacterias con respecto a T1 y T2. La labranza de conservación debe ser tenida en cuenta para un mejor manejo de los suelos de la zona.

Palabras clave: Conservación, compactación, microorganismos, siembra directa, sostenibilidad. 


\begin{abstract}
Based on the negative effects of conventional tillage in Inceptisoil at Villanueva, department of Casanare, Oriente of Colombia, the present investigation evaluated the impact of three tillage systems: T1: Reduced tillage (brushcutter, vibratory chisel, harrowing and sowing), T2: direct sowing and T3: conservation tillage (brushcutter, vibratory chisel, sowing with 30\% crop residues) on some physical, chemical and biological soil variables, such as bulk density (Da ), porosity (n), percentage of soil organic matter (\%SOM) and colony forming units of fungi and bacteria CFUs. A completely randomized block design was used with three treatments and five repetitions for 15 experimental units, evaluated in two periods: M1: before preparation and M2: after two months of corn sowing. Analysis of variance and Tukey's mean comparison test $(\mathrm{p} \leq 0.05)$ was performed. The Da was higher in T1 $(1.52 \mathrm{~g} / \mathrm{cm} 3)$ in M1. The T3 got the lower Da in both seasons $(1.27 \mathrm{~g} / \mathrm{cm} 3)$ and a greater porosity without differences between samplings. The T2 produced the higher percentage of SOM in M2. T3 showed higher CFUs of fungi and bacteria with respect to $\mathrm{T} 1$ and $\mathrm{T} 2$. Conservation tillage must be taken into account for a better soils management.
\end{abstract}

Keywords: Conservation, compaction, microorganisms, direct sowing, sustainability.

\section{INTRODUCCIÓN}

La labranza radica en manipular mecánicamente el suelo haciendo uso de diversos implementos de preparación, con el fin de alterar su estructura y disminuir la resistencia a la penetración de las raíces para convertirlo en un sustrato apropiado para la germinación de las semillas y el desarrollo productivo de los cultivos; además, corrige problemas específicos limitantes para el desarrollo de las raíces, identificados y diagnosticados previamente (Díaz et al., 2004). En los últimos años, se ha buscado que los procesos de preparación del suelo para el establecimiento de cultivos propendan por la sostenibilidad de los sistemas (Gómez et al., 2001; Martínez y Gómez, 2012).

Sin embargo, una fuerte y continua mecanización conlleva a la compactación (Ohep et al., 2002) y a la formación de costras y de piso de arado (Bravo, 1999). Produce cambios en el balance hídrico del suelo, disminuye la infiltración (Lal, 2014) y el intercambio gaseoso que afecta la actividad y número de microorganismos (Doran, 1998; Hernández y López, 2002). Así mismo, las actividades de labranza tradicional contribuyen a acelerar los procesos de erosión que llevan a la degradación del suelo y a largo plazo, a la disminución de la producción (Hernández y López, 2002).

A pesar que en el país se ha logrado avanzar en materia de preparación sostenible de suelos, principalmente de la siembra directa, en el municipio de Villanueva, (Casanare, Colombia), no se presenta una adopción masiva de éste método y hay escepticismo respecto a los beneficios para el suelo y las ganancias económicas que se podrían lograr; aun sabiendo que el uso permanente e intensivo de implementos agrícolas causa deterioro del suelo, según Amézquita et al. (1997), productores de arroz secano prefieren abandonar los lotes después de haberlos trabajado con labranza tradicional durante cinco a ocho años, al encontrar disminución en los rendimientos a causa de la degradación del suelo.

La degradación del suelo se puede medir a través de indicadores de calidad, entre los que se encuentra el contenido de materia orgánica (M.0) (Navarro et al., 2008), la actividad microbiológica (Acosta et al., 2010), las cuales varían espacialmente en el suelo y están relacionadas con la porosidad y la humedad del mismo. Tanto la M.0, como la porosidad y humedad influyen directamente en la recuperación 
de la estructura y estabilidad cuando a los suelos se le realizan diferentes tipos de manejo (Báez y Aguirre, 2011). La densidad aparente también hace parte de las variables a medir para cuando se busca evaluar la calidad de un suelo. Su interpretación sirve como indicador de la compactación, estructura, la resistencia mecánica y la cohesión del mismo (Martínez y Gómez, 2012); es así, si hay valores bajos de densidad aparente $\left(1-1,3 \mathrm{~g} / \mathrm{cm}^{3}\right)$ se suministra una condición física favorable para la siembra de cultivos (Hernández y López, 2002).

Con base en lo anterior, el propósito de esta investigación fue evaluar algunas propiedades físicoquímicas del suelo y la población de microorganismos en tres sistemas de labranza (reducida, de conservación y labranza cero o siembra directa), en dos épocas de muestreo, en la granja experimental Tahúr y la Banqueta de la Universidad de los Llanos, Villanueva Casanare.

\section{MATERIALES Y MÉTODOS}

El experimento se llevó a cabo en la Granja Experimental de la Universidad de los Llanos, localizada en el municipio de Villanueva, Casanare (Colombia) a $4^{\circ} 21^{\prime} 57^{\prime \prime} \mathrm{LN}$ y $72^{\circ} 46^{\prime} 01^{\prime \prime} \mathrm{L} 0$, a $225 \mathrm{msnm}$. Los suelos característicos de esta región son del orden Inceptisoles de régimen de humedad Ústico, con textura arcillosa y $\mathrm{pH}$ fuertemente ácido variando de 4,0 a 5,0 (IGAC, 2015). La temperatura promedio es de $25,7^{\circ} \mathrm{C}$ y la precipitación anual de $2976 \mathrm{~mm}$.

El área de lote experimental fue de 1 ha, la cual había sido manejada con labranza reducida y siembra directa, con rotación soya-maíz durante tres años previos al inicio del experimento. El cultivo que estaba establecido inmediatamente anterior al experimento era soya. Se trabajó con maíz y se utilizó un diseño experimental de Bloques Completamente al Azar con diseño factorial, donde el factor, sistemas de labranza correspondió a 3 tratamientos o niveles y el factor épocas de muestreo en dos niveles; se trabajaron 4 repeticiones, para un total de 12 unidades experimentales por muestreo. A continuación se describen los tratamientos en cada factor:

T1=Labranzareducida(LR) (pase dedesbrozadora dos meses después de la cosecha de soya, un pase de cincel vibratorio, un pase de rastra y siembra con sembradora de grano grueso).

T2= Siembra directa (SD) (herbicida, ningún pase de cincel o rastra, siembra con sembradora de grano grueso para siembra directa).

T3= Labranza de conservación (LC) (pase de desbrozadora dos meses después de la cosecha de soya, un pase de cincel vibratorio, siembra con sembradora de grano grueso, con 30\% de cobertura).

Las muestras de suelo se tomaron en dos épocas de muestreo: antes de la preparación (M1) y después de la preparación (M2). Cada parcela experimental se diseñó con un área de $20 \mathrm{~m}^{2}(10 \times 2 \mathrm{~m})$ y para evitar el efecto de bordes se dejó un área útil de $13,5 m^{2}(9 \times 1,5 m)$.

En cada una de las parcelas experimentales se determinó la densidad aparente (Da) mediante el método del cilindro de volumen conocido según metodología descrita por el IGAC (2006) y ese valor se utilizó para calcular la porosidad total (n \%).

En las dos épocas, se tomaron cinco muestras simples de suelo a profundidad de 0 a $20 \mathrm{~cm}$, en cada unidad experimental, a fin de analizar el contenido de porcentaje de materia orgánica (\%MOS) por el método de Walkley y Black (1934) y conteo de UFCs de microorganismos (hongos y bacterias).

Para el recuento de unidades formadoras de colonias UFCs de hongos y bacterias, las muestras fueron procesadas en el Laboratorio de la Universidad de los Llanos, de acuerdo con la metodología propuesta por Valencia (2004). Para el crecimiento de hongos se utilizó el medio de cultivo papa agar dextrosa (PDA) y para el crecimiento de las bacterias se utilizó agar nutritivo. 
Las UFCs están expresadas en número de UFC g-1 de suelo, se utilizó la siguiente fórmula:

$\mathrm{UFC}=(\#$ colonias en la caja de Petri $\mathrm{x} F) / \mathrm{MS}$

\section{Dónde:}

$\mathrm{UFC}=$ Unidades formadoras de colonia; $\mathrm{F}=$ Factor de dilución; y MS = ml de muestra de suelo aplicado en la caja

Los resultados de Da, porosidad n y \%MOS, se sometieron al Análisis de Varianza y pruebas de comparación de medias de Tukey $(\mathrm{p} \leq 0,05)$ utilizando el software InfoStat versión 2016.

\section{RESULTADOS Y DISCUSIÓN}

Densidad aparente (Da) y Porosidad total (n). Los resultados muestran interacción entre épocas de muestreo y tratamientos de labranza $(\mathrm{p} \leq 0,05)$. En los tres sistemas de labranza, los valores de Da y $\mathrm{n}$ se encontraron en un rango que variaron desde $1,27 \mathrm{~g} / \mathrm{cm}^{3}$ en labranza de conservación a 1,52g/ $\mathrm{cm}^{3}$ en labranza reducida y de n $42,5 \%$ en labranza reducida a 52,1\% en labranza de conservación (Figura 1 y 2). Según Baquero (2001), aquellos suelos que presentan valores de Da mayor a $1,5 \mathrm{~g} / \mathrm{cm}^{3}$ y $\mathrm{n}$ menor al 40\%, reflejan algún nivel de degradación física que afecta la mayoría de cultivos. Los valores más altos de Da y menor n son obtenidos con T1 sistemas de labranza reducida y rotación de cultivos maíz-soya.

En labranza reducida, se encontró que únicamente la Da tuvo una disminución significativa $(p \leq 0,05)$ entre muestreos, pasando de 1,52 a 1,28g/ $\mathrm{cm}^{3}$ (Figura 1). Esto se vio reflejado en un aumento significativo de la p del suelo que varió de 42,5 a 51,6\% (Figura 2). Varias investigaciones han demostrado que los efectos de diferentes tipos de labranza sobre las propiedades físicas de suelo no son apreciables en periodos cortos (un ciclo productivo) (Gómez et al., 2001; Zamorano et al., 2002; Díaz et al., 2004; Ceballos et al., 2010; Acosta-Martínez et al., 2010), tal como se observó en siembra directa y labranza de conservación.

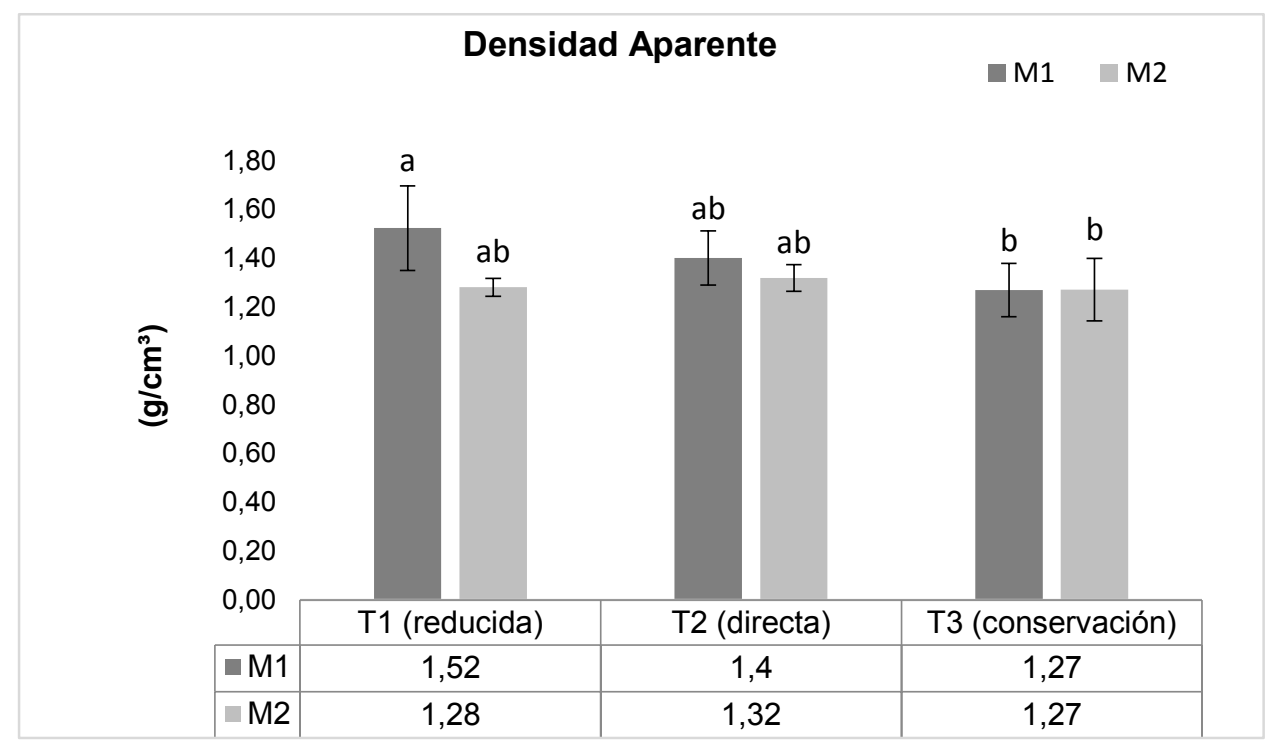

Medias con la misma letra no difieren significativamente $(\mathrm{p} \leq 0,05)$. M1=Antes de la preparación. M2=Después de la preparación.

Figura 1. Efecto de tipos de labranza y dos épocas de muestreo (M1 y M2) en la densidad aparente Da. 


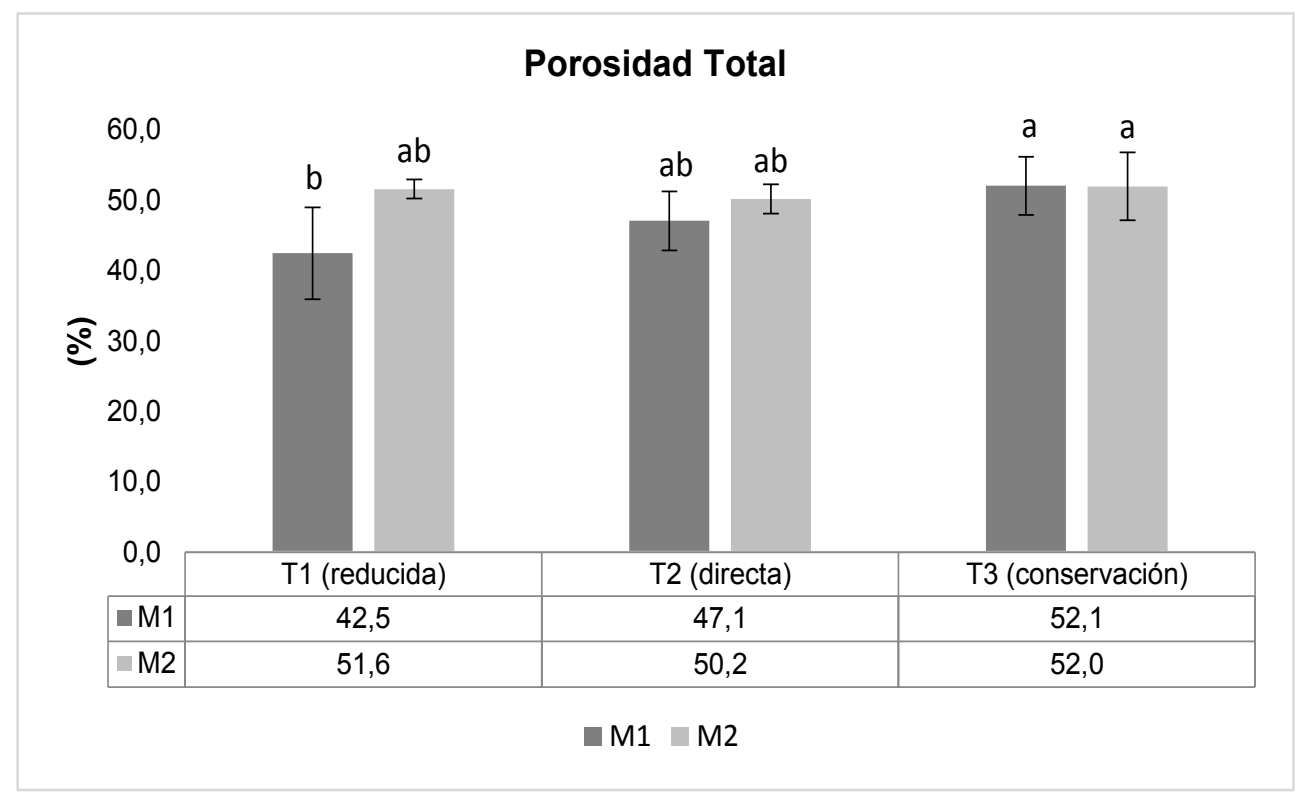

Medias con la misma letra no difieren significativamente $(\mathrm{p} \leq 0,05)$. M1=Antes de la preparación. M2=Después de la preparación.

Figura 2. Efectos de tipos de labranza y dos épocas de muestreo (M1 y M2) en la porosidad total.

La labranza mínima acompañada de coberturas y abonos verdes por un periodo de cuatro años no causó cambios significativos en la Da de un Inceptisol, en comparación con la labranza convencional (Zamorano et al., 2002). Sin embargo, un efecto significativo de las prácticas de mecanización sobre las propiedades físicas se logra apreciar en el largo plazo. Esto se debe a que dichas propiedades son más dependientes de la frecuencia y la intensidad de las labores (Wagger y Denton, 1989, Osunbitan et al., 2005).

Por otra parte, la Da en la labranza reducida (T1) fue igual a la directa (T2) y a su vez diferente a la labranza de conservación (T3) $(\mathrm{p} \leq 0,05)$ (Figura 1). Estos resultados fueron diferentes de los de Yoo y Wander (2006) al comparar el efecto de la labranza convencional con la labranza cero en suelos franco-limosos y arcillo-limosos de dos localidades de Illinois durante tres años, la labranza cero incrementó significativamente la $\mathrm{Da}$, en ambos suelos molisoles con poco drenaje (Da de 1,32 y 1,39g/ $\mathrm{cm}^{3}$, respectivamente). Díaz et al. (2004) reportaron que al evaluar la Da en los sistemas de labranza cero y labranza convencional no encontraron diferencias significativas. López et al. (2010) compararon labranza convencional y de conservación con diferente fertilización, sin diferencias significativas en la Da durante un año de estudio.

Según Zamorano et al. (2002), la tendencia en la disminución de la Da en suelos mecanizados seguramente se presenta debido al disturbio de los agregados del suelo por acciones naturales o antrópicas. Los métodos agrícolas de producción convencional de cultivos se han concentrado en la labranza intensiva, suministro de insumos externos como estrategia para incrementar la fertilidad del suelo y el rendimiento de la cosecha. Sin embargo, las consecuencias de la labranza intensiva son la compactación del suelo, la pérdida de la biodiversidad, así como el incremento de la erosión (Lal, 2014). 
Los efectos de la mecanización son altamente dependientes de las particularidades de cada suelo y las labores que implican menor alteración van a llevar a una mejor consolidación del mismo. Estas prácticas de labranza sostenible deben ser promovidas principalmente en suelos con alto riesgo de erosión (Lal, 2014; Seben et al., 2014). Su implementación en terrenos planos, compactados o anegables, debe ser alternada en los ciclos productivos con mecanización profunda para mejorar el drenaje del suelo y evitar su compactación (Lal, 2014).

\section{Contenido de materia orgánica del suelo} (\%MOS). El contenido de M.O del suelo en los tres tratamientos de labranza fueron bajos $(<2,0 \%)$ en todos los muestreos (Figura 3), lo que sugiere que los suelos de ésta zona presentan algún grado de degradación y requieren procesos de recuperación; sin embargo, no solo la M.O es un indicador de degradación de los suelos, existen otros factores físico, químicos y biológicos, como la infiltración, conductividad hidráulica, salinización, acidificación, biomasa microbiana, entre otros (Navarro et al., 2008).
El suelo bajo siembra directa (T2) y labranza de conservación (T3) mostraron mayores \%MOS, sin diferencias entre muestreos (Figura 3). Prause y Soler (2001), no encontraron diferencias entre los tratamientos de labranza conservacionista y siembra directa, la acumulación de los residuos de cosecha se realiza principalmente en los primeros centímetros del suelo tanto para siembra directa como para labranza de conservación, influyendo en los resultados.

Con respecto a la labranza reducida, MOS fue menor $(1,28 \%)$. Estos valores se mantuvieron al final del experimento sin diferencias significativas con el primer muestreo $(p \leq 0,05)$ (Figura 3). El \%MOS obtenido en siembra directa (T2) fue significativamente mayor a la obtenida en el suelo con labranza reducida (T1) y de conservación (T3), que fueron iguales ( $\mathrm{p} \leq 0,05)$, al final del experimento (Figura 3). Hernández y López (2002) afirman que al comparar tres modelos de labranza, la siembra directa propicia un mejor funcionamiento del suelo y favorece los compartimentos de materia orgánica que conservan el $\mathrm{N}$ y el $\mathrm{C}$ en un plazo largo de tiempo y se minimiza la activación de los procesos de erosión por una alta estabilidad de los agregados.

\section{Materia Orgánica}

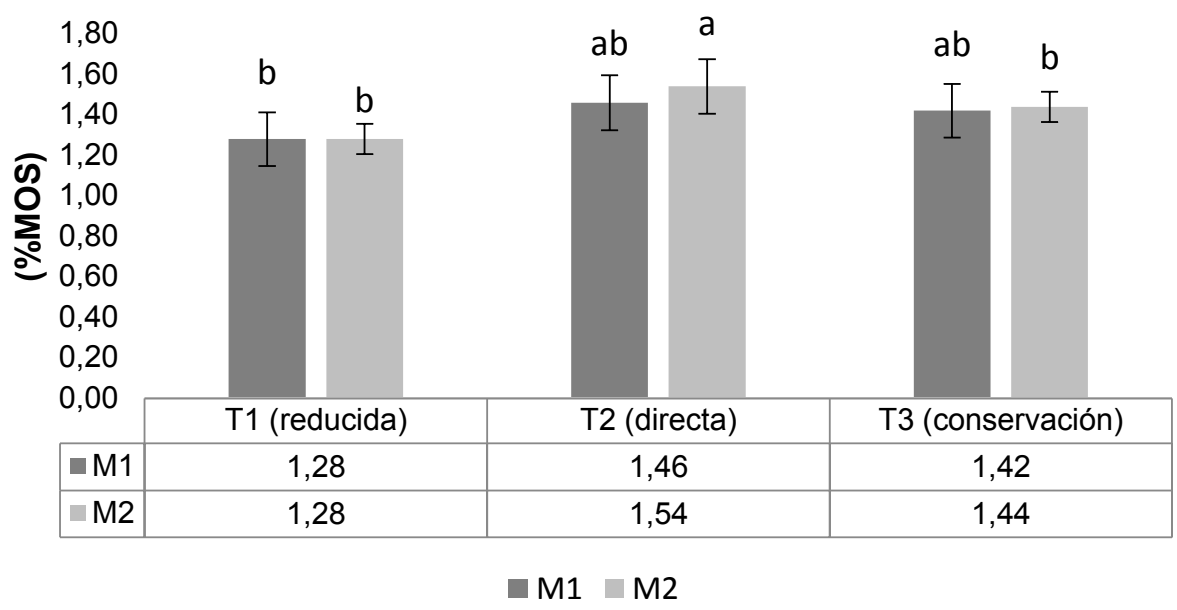

Medias con la misma letra no difieren significativamente $(\mathrm{p} \leq 0,05)$. M1=Antes de la preparación. M2=Después de la preparación.

Figura 3. Porcentaje de materia orgánica del suelo en las dos épocas de muestreo por efecto de diferentes tipos de labranza. 
En un estudio realizado por Rodríguez et al. (2000), se encontró que la Da disminuyó con el aumento de la MOS cuando se realiza labranza con cincel, pero cuando se hace la preparación con rastra no se presenta una relación clara entre la Da y MOS. En éste sentido, para el caso de siembra directa (T2) que presentó un mayor MOS al final del experimento, igualmente no se ve relación directa con la disminución de la Da. Se presentó una disminución significativa de la Da en la labranza reducida (T1), la cual a su vez no presentó aumentos en el \%MOS entre muestreos.

Población de hongos y bacterias (UFCs). La condición biológica del suelo es muy sensible a los disturbios ocasionados por el laboreo. En cuanto a la población de microorganismos se encontró que la mayor presencia de UFCs de hongos se presentaron en la labranza de conservación en el segundo muestreo 5,46 UFCs x $10^{5} \mathrm{~g}^{-1}$ suelo $(\mathrm{p} \leq 0,05)($ Tabla 1). El número y la actividad de los microorganismos están controlados parcialmente por la cantidad de energía que pueda liberarse en la descomposición de la MOS y no importa cuántas etapas o qué organismos intervienen en su degradación (Julca-Otiniano et al., 2006).

En cuanto a los géneros de hongos encontrados en los tres tratamientos se identificaron diez, Paecelomyces sp., Aspergillus sp., Mucor sp., Rhizoctonia sp., Penicillium sp., Fusarium sp., Curvularia sp., Gliocladium sp., Rhizopus sp. y Trichoderma sp. Según Garbeva et al. (2004) y Schapovaloffa et al. (2015), el suelo es un importante reservorio de hongos ento- mopatógenos, antagonistas potenciales para el control de insectos plaga en cultivos.

La población de hongos no se vio disminuida con la labranza reducida (T1), pero se vio aumentada con la siembra directa (T2) y con la labranza de conservación (T3) $(\mathrm{p} \leq 0,05)$ (Tabla 1). Julca-Otiniano et al. (2006), registraron diferencias para la abundancia de hongos totales, siendo los primeros, $75 \%$ más abundantes en siembra directa que en labranza convencional. Los mismos autores afirman que las poblaciones de hongos totales, son buenos indicadores biológicos, por que reflejan el efecto benéfico de un manejo conservacionista.

En la siembra directa se presenta una importante estratificación de la materia orgánica (Julca-Otiniano et al., 2006). Esta fragmentación del suelo, puede favorecer la acción de los microorganismos sobre los compuestos químicos de menor estabilidad química.

Se encontró que los valores de colonias de bacterias fue mayor que la de hongos (Tabla 1 y 2), igualmente ocurrió en estudio de Julca-Otiniano et al. (2006), indicando que posiblemente es porque son microorganismos participantes de la nitrificación y amonificación, importantes para la disponibilidad de nutrientes del suelo. La población fungosa predomina en suelos ricos en restos vegetales, donde la competencia por alimentos y energía no es demasiado aguda, pero declinan rápidamente cuando desaparecen los materiales fácilmente degradables; en cambio, las bacterias persisten más tiempo y consumen a los hongos (Julca-Otiniano et al., 2006).

Tabla 1. Unidades Formadoras de Colonias UFCs de hongos para las dos épocas de muestreo por efecto de diferentes tipos de labranza en un suelo Inceptisol de Casanare (Colombia)

\begin{tabular}{llll}
\hline Tratamiento & Hongos & Muestreo 1 & Muestreo 2 \\
\hline T1: Labranza Reducida & UFC/g suelo & $3,13 \times 10^{5} \mathrm{a}$ & $4,06 \times 10^{5} \mathrm{a}$ \\
T2: Siembra Directa & UFC/g suelo & $1,06 \times 10^{5} \mathrm{c}$ & $2,33 \times 10^{5} \mathrm{~b}$ \\
T3: Labranza de Conservación & UFC/g suelo & $2,93 \times 10^{5} \mathrm{~b}$ & $5,46 \times 10^{5} \mathrm{a}$ \\
\hline
\end{tabular}

Medias con la misma letra no difieren significativamente $(\mathrm{p} \leq 0,05)$. M1=Antes de la preparación. M2=Después de la preparación. 
Tabla 2. Unidades Formadoras de Colonias UFCs de bacterias para las dos épocas de muestreo por efecto de diferentes tipos de labranza

\begin{tabular}{llll}
\hline Tratamiento & Hongos & Muestreo 1 & Muestreo 2 \\
\hline T1: Labranza Reducida & UFC/g suelo & $1,00 \times 10^{6} \mathrm{c}$ & $9,13 \times 10^{6} \mathrm{a}$ \\
T2: Siembra Directa & UFC/g suelo & $5,33 \times 10^{6} \mathrm{~b}$ & $1,53 \times 10^{6} \mathrm{c}$ \\
T3: Labranza de Conservación & UFC/g suelo & $9,40 \times 10^{6} \mathrm{a}$ & $9,66 \times 10^{6} \mathrm{a}$ \\
\hline
\end{tabular}

Medias con la misma letra no difieren significativamente $(\mathrm{p} \leq 0,05)$. M1=Antes de la preparación. M2=Después de la preparación.

La labranza reducida fue la que más afectó el incremento de bacterias entre los dos muestreos, debido a aumentos en la porosidad del suelo y la MOS, valores coincidentes con los obtenidos por Hernández-Flores et al. (2013), quienes evaluaron la densidad de poblaciones bacterianas en niveles de 1 × $10^{2}$ a $6,6 \times 10^{3}$ UFC g $^{-1}$ de suelo, que son valores muy bajos para suelos con actividad agrícola, la cual sugiere el efecto negativo de la aplicación de agroquímicos sobre las poblaciones microbianas del suelo. En tanto que con la siembra directa se redujo y con la labranza de conservación se mantuvo $(\mathrm{p} \leq 0,05)$ (Tabla 2).

Las prácticas de labranza mínima o reducida reflejan mayor presencia de los microorganismos del suelo, puesto que este sistema de labranza favorece la acumulación e incorporación de residuos vegetales sobre la superficie del suelo (Spedding et al. 2004; Entry et al., 1996).

Los organismos del suelo juegan un papel crucial en muchos procesos que sustentan la calidad del suelo, por esta razón, el tamaño de la biomasa microbiana del suelo, la respiración, la mineralización, el potencial de nitrógeno, las actividades enzimáticas, la abundancia de hongos, nematodos y lombrices han sido utilizados como indicadores de calidad de suelo (Doran, 1998; Wei et al., 2013). Jaurixje et al. (2013) concluyen que el mejoramiento de las condiciones físicas del suelo, se traduce en una mayor actividad biológica de los microorganismos, con presencia de suelo que son organismos aeróbicos, en contraposición, un estado de inundación o compactación por períodos largos, el suelo se vuelve anaeróbico perdiendo su componente fungal.

En general, las prácticas de conservación han mostrado mejora en la productividad del recurso suelo al reducir la erosión, las pérdidas de materia orgánica y de nutrientes (Fuentes et al., 2009). Al implementar sistemas de labranza sostenibles como la siembra directa y de conservación, las propiedades físicas y biológicas del suelo tienden a mejorar (Doran, 1998). La labranza de conservación presentó menor densidad aparente Da y mayor porosidad total, que los otros tratamientos y la población más elevada de microorganismos, coincidiendo con éstos autores.

\section{CONCLUSIONES}

La población de hongos y bacterias se mostró favorecida con la labranza de conservación (T3), ya que se mejoraron las propiedades físicas del suelo. La siembra directa (T2) aumentó el porcentaje de la materia orgánica del suelo.

\section{AGRADECIMIENTOS}

A la Dirección General de Investigaciones de la Universidad de los Llanos por el apoyo financiero y de gestión, a los Laboratorios de Microbiología y 
de Suelos de la Universidad de los Llanos y todos aquellos colaboradores que aportaron en la logística del desarrollo del proyecto.

Conflicto de intereses: Los autores declaran que no hay conflicto de interés.

\section{REFERENCIAS BIBLIOGRÁFICAS}

Acosta-Martínez, V., Bell, C.W., Morris, B.E.L., Zak, J. \& Allen, V.G. (2010). Long-term soil microbial community and enzyme activity responses to an integrated cropping-livestock system in a semi-arid region. Agriculture, Ecosystems \& Environment. 137: 231240.

Amézquita, E., Sanz, J.I., Thomas, R.J., Vera, R.R., Hoyos, P., Molina, D.L. \& Chávez, L.F. (1997). Características estructurales de los suelos de los Llanos Orientales de Colombia sometidos a varios sistemas de manejo. Revista Suelos Ecuatoriales 27:151-156.

Báez, M. \& Aguirre, J. (2011). Efecto de la Labranza de conservación sobre las propiedades del suelo. Terra Latinoamericana. 29 (2): 113-121.

Baquero, A., Aristisabal, D., Rendon, W. \& Salamanca, C. (2001). Manejo conservacionista de los suelos arroceros de la Orinoquia colombiana. Boletín Técnico No. 32. Villavicencio: CORPOICA-PRONATTA. 44 p.

Bravo, C. (1999). Nivel de cobertura, conservación de suelos y aguas bajo diferentes sistemas de labranza. Revista Facultad de Agronomía. 25: 57-74.

Ceballos, D. Hernández, 0. \& Vélez, J. (2010). Efecto de la labranza sobre las propiedades físicas de un andisol del departamento de Nariño. Revista de Agronomía. 25 (1): 40-48.

Díaz, M., Grove, J., Murdock, L., Herbeck, J. \& Perfect, E. (2004). Soil structural disturbance effects on crop yields and soil properties in a no-till production system. Agronomy Journal. 96: 1651-1659.

Doran, J., Elliott, E., \& Paustian, K. (1998). Soil microbial activity, nitrogen cyclin, and longterm changes in organic carbon pools as related to fallow tillage management. Soil and Tillage Research. 49 (1): 3-18.
Entry, I., Mitchell, C. \& Backman, C. (1996). Influence of management practices on soil organic matter, microbial biomass and cotton yield in Alabamas "old rotation". Biology and Fertility of Soils. 23(4): 353358. doi: 10.1007/BF00335906.

Fuentes, M., Govaerts, B., De León, F., Hidalgo, C., Dendoovend, L., Sayre, K. \& Etchevers, J. (2009). Fourteen years of applying zero and conventional tillage, crop rotation andresidue management systems and its effect on physical and chemicalsoil quality. European Journal of Agronomy. 30: 228-237.

Garbeva, P., Van Veen, J.A. \& Van Elsas, J.D. (2004). Microbial diversity in soil: Selection of microbial populations by plant and soil type and implications for disease suppressiveness. Annual Review of Phytopathology. 42: 243-270.

Gómez, E., Ferreras, L., Toresani, S., Ausilio, A. \& Bisaro, $V$. (2001). Changes in some soil properties in a Vertic Argiudoll under short-term conservation tillage. Soil and Tillage Research. 61(3-4): 179-186. doi: 10.1016/S0167-1987(01)00193-3.

Hernández-Flores, L., Munive-Hernandez, J. A., Sandoval-Castro, E., Martínez-Carrera, D.; \& Villegas-Hernández, M.C. (2013). Efecto de las prácticas agrícolas sobre las poblaciones bacterianas del suelo en sistemas de cultivo en Chihuahua, México. Revista Mexicana de Ciencias Agrícolas. 4(3): 353-365.

Hernández, R. \& López, D. (2002). El tipo de labranza como un agente modificador de la materia orgánica: un modelo para suelos de sabana de los Llanos Centrales Venezolanos. Interciencia. 27 (10): 529-536.

IGAC - Instituto Geográfico Agustín Codazzi. (2006). Métodos analíticos de laboratorio de suelos. Sexta edición. Bogotá: Imprenta nacional de Colombia. 648p.

IGAC - Instituto Geográfico Agustín Codazzi. (2015). Estudio general de suelos y zonificación de tierras departamento de Casanare, Escala 1:100000. IGAC. $413 \mathrm{p}$.

Jaurixje, M., Torres, D., Mendoza, B., Henriquez, M. \& Contreras, J. (2013) Propiedades físicas y químicas del suelo y su relación con la actividad biológica bajo diferentes manejos en la zona de Quíbor, Estado Lara. Bioagro. 25 (1): 47-56. 
Julca-Otiniano, A., Meneses-Florian, L., Blas-Sevillano, R. \& Bello-Amez, S. (2006). La materia orgánica, importancia y experiencia de su uso en la agricultura. Idesia. 24 (1): 49-61. doi: http://dx.doi. org/10.4067/S0718-34292006000100009.

Martínez, A. \& Gómez, J. (2012). Elección de los agricultores en la adopción de tecnologías de manejo de suelos en el sistema de producción de algodón y sus cultivos de rotación en el valle cálido del alto magdalena. Revista Corpoica. 13 (1): 62-70.

Navarro, A., Figueroa, B., Martínez, M., Gonzalez, F. \& Salvador, E. (2008). Indicadores físicos del suelo bajo labranza de conservación y su relación con el rendimiento de tres cultivos. Agricultura Técnica en México. 34 (2):151-158.

Lal, R. (2014). Societal value of soil carbon. Journal of Soil and Water Conservation. 69(6): 186A-192A. doi: http://dx.doi.org/10.2489/jswc.69.6.186A.

López, J., Vazquez, C., Salazar, E., Zúñiga, R. \& Trejo, H. (2010). Sistemas de labranza y Efectos de la labranza sobre algunas variables físicas en un suelo 0xic Haplustalf del Yaracuy medio bajo cultivo de maíz fertilización en la producción de maíz forrajero. Revista Internacional de Botánica Experimental. 79: 47-54.

Ohep, C., Marcano, F., Pudzzar, S. \& Colmenárez, C. (2002). Efectos de la labranza conservacionista en los atributos físicos del suelo que influyen sobre el rendimiento del maíz. Bioagro. 14 (1): 37-45.

Osunbitan, J. A., Oyedele, D. J. \& Adekalu, K. O. (2005). Tillage effects on bulk density, hydraulic conductivity and strength of a loamy sand soil in Southwestern Nigeria. Soil and Tillage Research. 82(1): 57-64. doi: http://dx.doi.org/10.1016/j.still.2004.05.007.

Prause, J. \& Soler, J. (2001). Cambios producidos en un suelo bajo labranza conservacionista y siembra directa de algodón en el Chaco, Argentina. Agric. Téc. 61 (4): 527-532. doi: http://dx.doi.org/10.4067/ S0365-28072001000400016.

Rodríguez, C., Herrera, 0. \& Madero, E. (2000). Efecto de la labanza en las propiedades físicas de un Vertisol Ustico y en la producción de sorgo, en el Valle del Cauca, Colombia. Acta Agronómica. 50 (1): 35-47.
Schapovaloffa, M., Angeli, L., Urrutiac, M. \& López, C. (2015). Natural ocurrence of entomopathogenic fungi in soils cultivated with Paraguay tea (Ilex paraguariensis St. Hil.) in Misiones, Argentina. Revista Argentina de Microbiología. 47 (2): 138-142. doi: http:// dx.doi.org/10.1016/j.ram.2015.03.005.

Seben, J., Getulio, C., José, E. \& Lal, Rattan. (2014). The effects of land use and soil management on the physical properties of an 0xisol in Southeast Brazil. Revista Brasileira de Ciência do Solo. 38(4): 1245-1255. doi: http://dx.doi.org/10.1590/S010006832014000400021.

Spedding, T. A., Hamel, C., Mehuys, G. R. \& Madramootoo, C. A. (2004). Soil microbial dynamics in maizegrowing soil under different tillage and residue management systems. Soil Biology and Biochemistry. 36(3): 499-512. doi: http://dx.doi.org/10.1016/j. soilbio.2003.10.026.

Valencia, H. (2004). Manual de prácticas de microbiología básica. Primera edición. Bogotá: Editorial Unibiblos, Universidad Nacional de Colombia. 46 p.

Wagger, M.G. \& Denton, H.P. (1989). Influence of cover crop and wheel traffic on soil physical properties in continuous no-till corn. Soil Science Society of America Journal. 53(4): 1206-1210. doi: 10.2136/sssaj1 989.03615995005300040036x.

Walkley, A \& Black, IA. (1934). An examination of Degtjareff method for determining soil organic matter and a proposed modification of the chromic acid titration method. Soil Sci. 37: 29-38.

Wei, F., Yu-qing, Z., Bin, W., Tian-shan, Z., Xin, S.Q., Chen-xi, S., Jia-bin, L., Zong-rui, L., Ke-yu, F. (2013). Influence of Disturbance on Soil Respiration in Biologically Crusted Soil during the Dry Season. The Scientific World Journal. Article ID 408560. 6 p. doi:10.1155/2013/408560.

Yoo, G. \& Wander, M. (2006). Influence of tillage practices on soil structural controls over carbon mineralization. Soil Science Society of America Journal. 70: 651-659.

Zamorano, A., Velazco, R. \& Prager, M. (2002). Efecto de cinco sistemas de manejo del suelo en las propiedades físicas de un typic distrandept en piendamo, Cauca. Acta Agronómica. 51 (1): 61-67. 